\title{
Ischaemic Limb Changes in Patients with Peripheral Arterial Disease (PAD) Associated with Coronary Artery Disease (CAD) \\ SM AHSAN HABIB ${ }^{1}$, MOHAMMAD SAFIUDDIN ${ }^{1}$, M NAZRUL ISLAM $^{1}$, KAMALPASHA $^{2}$, SALEH AHMED NURUL ALAM $^{3}$, KHALED MOHSIN ${ }^{2}$, KHANDAKAR QAMRUL ISLAM ${ }^{3}$, SABINA HASHEM ${ }^{3}$, TANJIMA PARVIN ${ }^{1}$, FAZLUR RAHMAN ${ }^{1}$, M SAIFULLAH KHAN \\ ${ }^{1}$ Department of Cardiology, Bangabandhu Sheikh Mujib Medical University, Dhaka, ${ }^{2}$ Department of Cardiology, Square Hospital, Dhaka, ${ }^{3}$ National Institute of Cardiovascular Diseases, Dhaka, ${ }^{4}$ Department of Vascular Surgery, Bangabandhu Sheikh Mujib Medical University, Dhaka
}

Address for Correspondence : Dr. SM Ahsan Habib, Associate Professor, Department of Cardiology, Bangabandhu Sheikh Mujib Medical University, Shahbagh, Dhaka-1000, Email: habib42a@hotmail.com

\begin{abstract}
:
To correlate magnitude and distribution of coronary Artery Disease (CAD) with ischaemic limb changes in patients with Peripheral Arterial Disease (PAD) of lower limbs.Most common cause of PAD is atherosclerosis. Atherosclerosis is a generalized disease and often atherosclerotic CAD is associated with PAD. Because of ischaemic limb changes in patient with PAD they do not always experience angina even after having CAD. This prospective observational study was conducted in National Institute of cardiovascular Diseases (NICVD) Dhaka, Bangladesh during July 2004 to June 2005. Total 58 patients with PAD were included in the study. Patients were classified as group I having normal coronary artery, group-II insignificant CAD (L M $<50 \%$

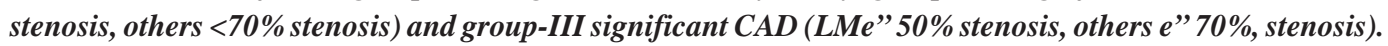
Ischaemic limb changes was significantly higher in patients with CAD compare to non-coronary artery disease $(P=0.047)$. This study suggests that ischaemic limb changes had significant relation with the presence of CAD.
\end{abstract}

Introduction:

Patients with peripheral Arterial Disease (PAD) often present with coronary atherosclerosis and are at increased risk for adverse cardiovascular events. ${ }^{1-5}$ Ischaemic limb changes has been shown to be a strong predictor of subsequent cardiovascular events in patients with PAD of lower limb in middle aged population and older subjects ${ }^{6,7}$. Ischaemic limb changes was found to be independently and directly related to the extent of atherosclerosis in coronary and non coronary arterial beds, reflecting generalized atherosclerosis and could be useful in assessing the risk for cardiovascular events in patients with $C A D^{7-9}$. The main objective of the study was to correlate ischaemic limb changes with the severity and extent of CAD in patient suffering from clinically significant PAD of lower limbs.

\section{Patients and method:}

Patients with age 40 years and above were included. Relevant physical examination like pulses, blood pressure, elevation pallor, capillary filling, bruits, changes in skin \& appendages, new healing ulcer, and gangrene were included. Patients age below 40 years and suspected systemic vasculitis were excluded. Informed written consent was taken from each patient. Baseline clinical data, physical examination, $\mathrm{ABI}$, peripheral and coronary angiogram were done in all patients. This prospective observational study was conducted in National Institute of Cardiovascular Diseases (NICVD), Dhaka during July 2004 to July 2005. Total 58 patients with PAD were included in the study. patients were classified as group I having normal coronary artery, group-II insignificant CAD (LM $<50 \%$ stenosis, others $<70 \%$ stenosis) and group-III significant CAD (LM $\geq 50 \%$ stenosis, others $\geq 70 \%$ stenosis)

\section{Coronary and Peripheral Angiogram:}

Peripheral angiogram and CAG were done in all the patients. Both angiograms were done by retrograde femoral approach and radio-iodinated contrast media were used. In peripheral arteriography, pigtail multipurpose or right judkins and in CAG both right and left judkins catheter were used. Routine views were taken after angiography patient. Population were divided into 3 group based on CAG findings.

\section{Results:}

Table I shows that among the 58 patients included in the study 52 were male and 6 were female. 
Table-I

Distribution of patients by age and sex $(n=58)$.

\begin{tabular}{|c|c|c|c|c|c|c|c|}
\hline \multirow[t]{3}{*}{ Age in years } & \multicolumn{4}{|c|}{ Sex } & \multicolumn{2}{|c|}{ Total } & \multirow[t]{3}{*}{ *p value } \\
\hline & \multicolumn{2}{|c|}{ Male } & \multicolumn{2}{|c|}{ Female } & - & & \\
\hline & No. & $\%$ & No. & $\%$ & No. & $\%$ & \\
\hline $40-49$ & 18 & 34.6 & 2 & 33.3 & 20 & 34.5 & \\
\hline 50-59 & 23 & 44.2 & 1 & 16.7 & 24 & 41.4 & \\
\hline $60+$ & 11 & 21.2 & 3 & 50.0 & 14 & 24.1 & \\
\hline Total & 52 & 100.0 & 6 & 100.0 & 58 & 100.0 & \\
\hline Mean \pm SD & \multicolumn{2}{|c|}{$53.0 \pm 7.4$} & \multicolumn{2}{|c|}{$56.3 \pm 12.1$} & \multicolumn{2}{|c|}{$53.3 \pm 7.9$} & \\
\hline Range & \multicolumn{2}{|c|}{$40-75$} & \multicolumn{2}{|c|}{ 40-70 } & \multicolumn{2}{|c|}{$40-75$} & 0.331 \\
\hline
\end{tabular}

*p value reached from unpaired student's t test

The mean age of the patients were $53.3 \pm 7.9$ years ranging from 40 to 75 years. The mean age of the male patients was $53.0 \pm 704$ years and the female patients were $56.3 \pm 12.1$ years.

Figure 1 shows that out of 58 patients, $41.4 \%$ had no coronary arterial disease, $15.5 \%$ had insignificant coronary arterial disease that is $<50 \%$ stenosis in $\mathrm{LM}$ and $/$ or $<70 \%$ stenosis in other coronary artery and $43.1 \%$ had showed significant coronary arterial disease that is 50 and above percentage of stenosis in LM and / or 70\% and above stenosis in other coronary arteries. So overall $58.6 \%$ had coronary artery disease.

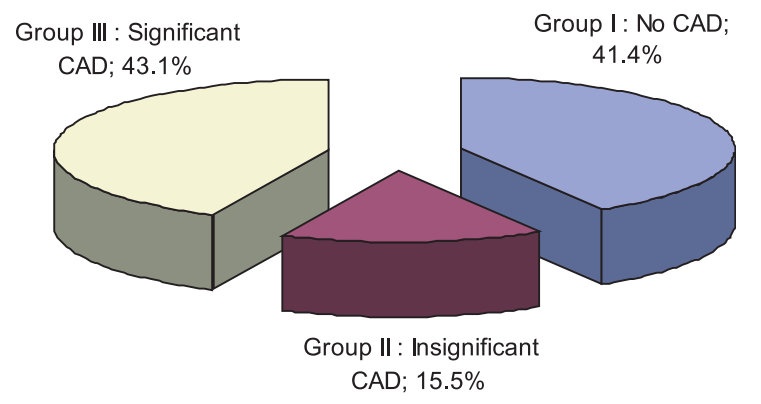

Fig 1: Distribution of patients by coronary artery disease Figure-2 shows major atherosclerotic risk factor profile of study population had highest of smoking (67.2\%) followed by diabetes mellitus (55.2\%), dyslipidacmia (51.7\%), family history of IHD (44.8\%) and hypertension (34.5\%).

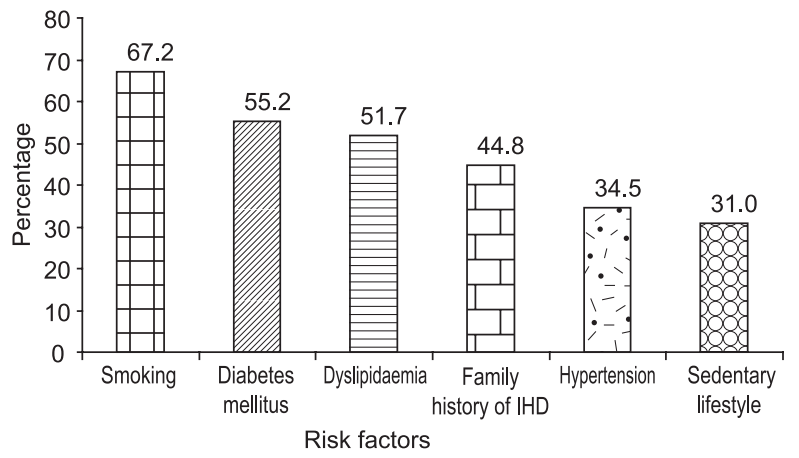

Fig 2: Distribution of patients by risk factors $(n=58)$
Table-II shows that among the patients with significant $\mathrm{CAD}$, highest percentage had gangrene in the peripheral lower limb (48\%) followed by non healing ulcer (40\%) and lowest changes in skin and appendages (12\%) where as among the patients with normal CAD,

\section{Table II}

Distribution of patients by coronary artery disease and ischemic limb changes

\begin{tabular}{|c|c|c|c|c|c|c|c|c|c|}
\hline \multirow{3}{*}{$\begin{array}{l}\text { Ischemic limb } \\
\text { changes }\end{array}$} & \multicolumn{6}{|c|}{ Coronary Artery Disease } & \multicolumn{2}{|c|}{ Total } & \multirow[t]{3}{*}{ *p value } \\
\hline & \multicolumn{2}{|c|}{ Group I } & \multicolumn{2}{|c|}{ Group II } & \multicolumn{2}{|c|}{ Group III } & \multirow[b]{2}{*}{ No. } & \multirow[b]{2}{*}{$\%$} & \\
\hline & No. & $\%$ & No. & $\%$ & No. & $\%$ & & & \\
\hline $\begin{array}{l}\text { Change in } \\
\text { skin and } \\
\text { appendages }\end{array}$ & 11 & 45.8 & 3 & 33.3 & 3 & 12.0 & 17 & 29.3 & 0.047 \\
\hline $\begin{array}{l}\text { Non-healing } \\
\text { ulcer }\end{array}$ & 8 & 33.3 & 3 & 33.3 & 10 & 40.0 & 21 & 36.2 & \\
\hline Gangrene & 5 & 20.8 & 3 & 33.3 & 12 & 48.0 & 20 & 34.5 & \\
\hline Total & 24 & 100.0 & 9 & 100.0 & 25 & 100.0 & 58 & 100.0 & \\
\hline
\end{tabular}

N.B.

Group I : Normal Coronary Artery

Group II : Insignificant Coronary Artery Disease

Group III : Significant Coronary Artery Disease

${ }^{*}$ p value reached from chi square test (CAD vs. No CAD)

Highest percentage had change in skin and appendages (45.8\%) followed by non healing ulcer (33.3\%) and gangrene $(20.8 \%)$ and the different was statistically significant $(\mathrm{P}<0.05 \%)$. This indicated that the proportion of gangrene were more in patients with significant CAD than the normal coronary arteries.

Figure-3 shows that-21 (36.2\%) patients had non heading ulcer followed by 20 (34.5\%) had gangrene and 17 (29.3\%) had changes in skin and appendages in peripheral lower limbs. 


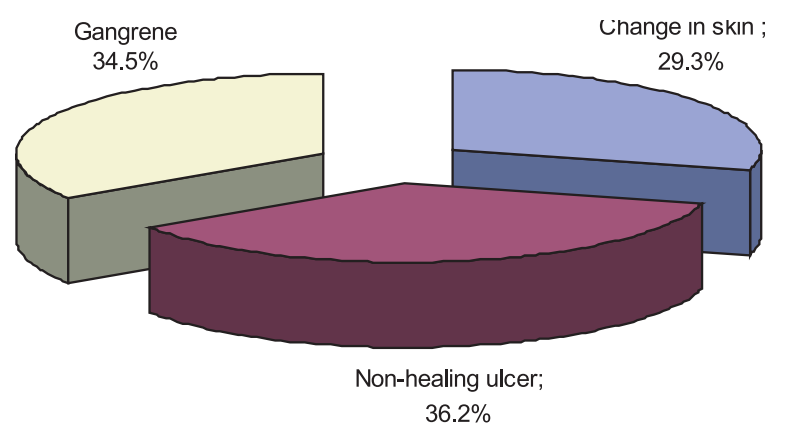

Fig.-3: Distribution of patients with PAD having ischaemic limb changes

\section{Discussion:}

It was concluded that ischaemic changes in lower limb directly related with extent and severity of CAD. Among the 58 patients included in the study 52 were male and 6 were female. It shows that small number of female patients with PAD of lower limbs attended the hospital for treatment. The age of the patients ranged from 40 years to 75 years and mean age $53.3 \pm 7.9$ years. Among the 58 patients 24(41.4\%) had no coronary artery disease; 9 (15.5\%) patients had insignificant coronary artery disease and $25(43.1 \%)$ patients had significant coronary artery disease. Data analysis revealed that the proportion of smoking, diabetes mellitus, dyslipidemia, family history of IHD, hypertension and sedentary life style was significantly higher in patients with CAD than non CAD. This is consistent with the study of Balasubramanian et al. (2004) in which it was found that in patients with peripheral vascular disease, coronary artery disease was associated with hypertension, smoking and dyslipidaemia. ${ }^{1,2}$ It was found that 21(36.2\%) patients had non healing ulcer in peripheral limb followed by 20(34.5\%) had gangrene and 17(29.3\%) had changes in skin. Analysis found that among the patients with significant coronary artery disease, highest percentage had gangrene in the peripheral limb (48.0\%) followed by non healing ulcer (40.0\%) and lowest change in skin (12.0\%) whereas among the patients with normal CAD, highest percentage had change in skin and appendages (45.8\%) followed by non healing ulcer (33.3\%) and gangrene (20.8\%) and the difference was statistically significant $(\mathrm{p}<0.05)$. This indicated that the proportion of gangrene were more in patients with significant coronary artery disease than the normal coronary artery.

\section{Conclusion:}

Patients with PAD are more likely to have CAD. In this study ischaemic limb changes had significant relation with severity of CAD. Coronary angiogram should be done in all cases of PAD especially in patients with ischaemic lower limb changes.

\section{References:}

1. Belch JF, Eric J, Topol, et al. Critical issues in peripheral arterial disease detection and management. Arch Intern Med 2003;163:884-892.

2. Hertzer NR., Bevan EG, Young JR, et al. Coronary artery disease in peripheral vascular patients. A classification of 1000 coronary angiograms and results of surgical management. Ann Surg1984;199(2):223-233.

3. Boon NA, Fox KAA, Bloomfield \& Bradbury. Cardiovascular disease, in Davidson's Principles and Practice of Medicine, $19^{\text {th }}$ ed, C. Haslett, O, EP. Chilvers, NA. Boon \& NR. Colledge, Churchill Livingstone, Edinburgh.2002; 358-481.

4. Peter FP, Grossi EA, Braumann FG et al. Silent myocardial ischemia monitoring predicts late as well as perioperative cardiac events in patients undergoing vascular surgery. J Vasc Surg1992;6(2):171-179.

5. Criqui M, Fronek A, Barrett-Connor E et al. The prevalence of peripheral arterial disease in a defined population. circulation 1985;71:510-5.

6. Criqui HM, Deneberg JO, Langer RD et al. The epidemiology of peripheral arterial disease: importance of identifying the populatoin at risk. Vasc Med 1997;2:221-6

7. Al Zahrami HA, AC Bar, HM, Bahnassi A et al. The distribution of peripheral arterial disease in a defined population of elderly high risk Saudi patients. Int Angiol1997; 16:123-8.

8. Creager MA, Libby P. Peripheral arterial disease, in A text book of cardiovascular medicine, $6^{\text {th }}$ ed. Braunwald, Zipes and Libby, W.B. Saunder's, Philadelphia 2001:1451-1478.

9. Papamichael CM, Lekakis JP, Stamatelopoulos K. Ankle brachial index as a predictor of the extent of coronary atherosclerosis and cardiovascular events in patients with coronary artery disease. The American Journal of Cardiology2000; 86:615-618. 